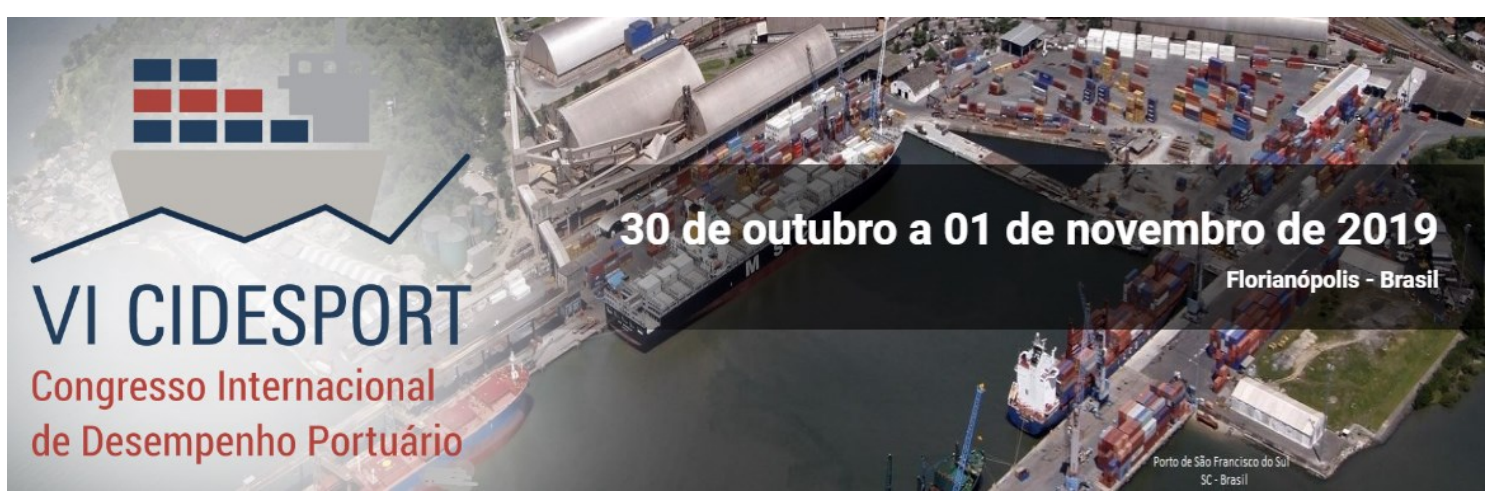

\title{
ASPECTOS CONTÁBEIS E TRIBUTÁRIOS NO REGISTRO DOS INVESTIMENTOS EM INFRAESTRUTURA PORTUÁRIA DE UM PORTO DELEGADO - O CASO DA SCPAR PORTO DE IMBITUBA S.A.
}

\author{
Elivelton Luiz Doré \\ SCpar Porto de Imbituba
}

Resumo: O presente relato técnico visa demonstrar os aspectos contábeis de mensuração e registro dos bens e investimentos realizados pela SCPar Porto de Imbituba S.A. na modernização de sua infraestrutura portuária a luz das Normas Internacionais de Contabilidade. A companhia administra o complexo portuário por intermédio de um convênio de delegação junto à União, no qual concedeu a exploração por prazo determinado de 25 anos, podendo ser prorrogado por igual período. Neste contexto, todos os ativos afetos a concessão são revertidos ao poder concedente ao término deste contrato, independente de indenização. $O$ trabalho resultou no entendimento de que os investimentos devem ser contabilizados como ativo intangível, conforme prevê a orientação técnica contábil OCPC 05 - Contratos de Concessão, aprovada pela Deliberação CVM n 654 de 28 de Dezembro de 2010. Além deste aspecto, o trabalho trouxe entendimento quanto aos aspectos tributários inerentes a esta forma de contabilização dos ativos.

Palavras chave: IFRS. Convênio de Delegação. Concessão.

\section{INTRODUÇÃO}

A empresa SCPar Porto de Imbituba S.A. teve sua origem com o propósito de administração da infraestrutura da área portuária de Imbituba/SC, conforme delegação da União ao estado de Santa Catarina por intermédio do Convênio de Delegação $n^{\circ}$ 01/2012, no qual concedeu a sua gestão por prazo determinado de 25 anos, podendo ser prorrogado por igual período.

Entre as diretrizes estabelecidas no convênio de delegação, uma grande parcela da aplicação das receitas obtidas pela empresa será destinada a investimentos em infraestrutura e melhorias nas instalações do complexo portuário.

Devido a diversas opiniões divergentes sobre a forma de reconhecimento contábil dos investimentos citados, o presente relato técnico busca demonstrar a forma mais prudente, conservadora e que reflita de forma mais fidedigna a real situação financeira da SCPar Porto de Imbituba S.A., contemplando a conformidade com os princípios fundamentais da contabilidade, utilizando-se da Legislação Societária vigente no Brasil, em especial as Normas Internacionais de Contabilidade - IFRS.

O presente trabalho busca também demonstrar as situações tributárias estabelecidas sobre o assunto, apresentando a forma menos onerosa possível de recolhimento de tributos, respeitando em sua integridade a legislação tributária federal brasileira.

${ }^{*}$ A revisão gramatical, ortográfica, ABNT ou APA foi realizada pelos autores. 


\title{
2 CONTEXTO
}

A SCPar Porto de Imbituba S.A. é uma empresa de Propósito Especifico, subsidiária integral da empresa SC Participações e Parcerias S.A, constituída com a finalidade de administração e exploração do Porto Organizado de Imbituba, no sul do Estado de Santa Catarina, por intermédio do Convênio de Delegação nº 01/2012 entre a União, através da Secretaria de Portos e o Estado de Santa Catarina.

Destacam-se como pontos fundamentais para interpretação da Legislação Contábil Societária no Brasil e a situação tributária perante os aspectos de mensuração dos investimentos relativos à reestruturação e investimentos realizados na área portuária, bem como a aquisição de bens de caráter permanente, conforme as situações descritas na sequência.

Conforme estabelecido na cláusula terceira, do Convênio de Delegação, constituem receitas do porto os recursos obtidos através da utilização da área portuária, sendo que os rendimentos auferidos devem ser destinados exclusivamente ao custeio de suas atividades, sua manutenção e melhoria, se não vejamos:

\begin{abstract}
Parágrafo Segundo: Constituirão receitas da Administração do Porto toda e qualquer remuneração proveniente do uso da infraestrutura aquaviária e terrestre, de armazenagem, de contratos de arrendamento de áreas e instalações, de aluguéis e de projetos associados, bem como de aplicações financeiras e oriundas de atividades complementares.

Parágrafo Terceiro: Todas as receitas da Autoridade Portuária deverão ser administradas e destinadas, pelo INTERVENIENTE DO DELEGATÁRIO, exclusivamente ao custeio das atividades delegadas, manutenção das instalações e investimentos no PORTO, sendo permitida, entretanto, a distribuição de lucros e dividendos aos acionistas ao final do exercício fiscal, no percentual não superior ao mínimo legal, conforme previsto nos artigos 109, I, 201 e 202 da Lei n 6.404/76.

Parágrafo Quarto: O delegatário, ou sua interveniente, aplicará os valores correspondentes a distribuição de lucros e dividendos a que se refere o parágrafo anterior em ações que reverterão em desenvolvimento ou melhoria das atividades do Porto, mediante aprovação prévia da DELEGANTE. (Cláusula Terceira, Convênio de Delegação nº 01/2012 00045.003085/2012-11).
\end{abstract}

Todos os recursos obtidos deverão ser destinados a atividades fim do Porto de Imbituba e seus lucros apurados reverterão em ações de desenvolvimento e melhoria do mesmo.

As obrigações da SCPar Porto de Imbituba S.A., empresa delegatária dos serviços públicos do porto, estão contidas na cláusula quarta, como dispõe a seguir:

V: Promover melhoramentos e a modernização do PORTO, implementando as obras destinadas a garantir a manutenção do serviço adequado, aumentar a sua segurança e a modicidade das tarifas do porto;

XIV - Manter atualizado o inventário e registro dos bens vinculados ao PORTO;

$\mathrm{XV}$ - Adotar medidas necessárias para que haja a manutenção e reposição de bens e equipamentos vinculados ao PORTO, bem como a aquisição de novos bens, de forma a assegurar a atualidade do aparelhamento do porto; XVI - Responsabilizar-se pela conservação dos bens patrimoniais do PORTO, pertencentes a delegante, incluindo a sua infraestrutura de proteção e acesso, constantes no inventário a ser realizado pela 
VI CIDESPORT/2019

Congresso Internacional

de Desempenho Portuário

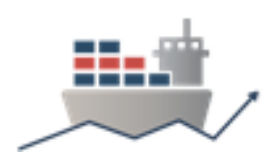

DELEGANTE, zelando pela integridade desses bens, mantendo-os em perfeita condição de conservação e funcionamento até a sua devolução a DELEGANTE.

XXIII - Devolver a DELEGANTE, ao final do prazo da delegação, todos os bens que lhe forem cedidos em decorrência do presente convênio. (Convênio de Delegação $n^{\circ}$ 01/2012 - 00045.003085/2012-11).

Conforme estabelecido, todos os bens pertencem ao poder delegante (União), sendo que cabe a SCPar Porto de Imbituba apenas seu direito de uso para posterior devolução ao término do contrato, sem nenhuma relação de propriedade ou controle junto a estes ativos.

A Cláusula quinta dispõe sobre o patrimônio do porto:

A delegante, o delegatário e a interveniente do delegatário indicarão, cada um, no prazo de quinze dias úteis, contados a partir da data de assinatura deste instrumento, um representante para compor a Comissão Especial, a ser instituída e coordenada pela INTERVENIENTE DA DELEGANTE, visando a avaliação, a inventariança, a entrega e ao recebimento dos bens a serem cedidos por força deste convênio, cabendo a INTERVENIENTE DO DELEGATÁRIO dar o necessário suporte técnico a comissão.

Parágrafo primeiro - até 150 (cento e cinqüenta) dias, contados da data de vigência deste instrumento, a Comissão a que se refere o caput, concluirá a avaliação e o inventário dos bens que integram o patrimônio do PORTO e que serão cedidos ao delegatário.

Paragráfo segundo - Concluido o inventário, a interveniente da delegante e o delegatário firmarão TERMO DE CESSÃO DE USO DE BENS, que também será firmado pela INTERVENIENTE DO DELEGATÁRIO, o qual deverá conter disposição expressa sobre sua reversão.

Paragráfo Terceiro - Os bens cedidos bem como os adquiridos durante a vigência do convenio para exploração do PORTO ficarão afetos ao seu patrimônio e reverterão a delegante, ao término deste convênio, independente de indenização. (Convênio de Delegação $n^{\circ}$ 01/2012 00045.003085/2012-11).

Conforme exposto, extinto o período de delegação, retornará a União todos os bens, direitos e privilégios vinculados à exploração do sistema portuário transferido à SCPar Porto de Imbituba ou por ela implantada no âmbito da sua delegação.

Recentemente foi normatizado pela Agência Nacional de Transportes Aquáviários a situação de controle patrimonial dos bens sob guarda da administração portuária, através da Resolução Normativa $n^{\circ} 029$ de 2019, esclarecendo em seus principais pontos que: "Art. 14. Caberá a cada administração portuária, por meio da Comissão Especial Permanente mencionada no art. 11 desta norma, solicitar à ANTAQ a autorização para a desincorporação de bens" e "Art. 29. A reversão de bens à União dar-se-á na ocasião da extinção do vínculo legal ou do contrato administrativo, atendendo-se às condições dos instrumentos jurídicos que os regem".

\section{INTERVENÇÃO}

\subsection{Normas Internacionais de Contabilidade}

A publicação da Lei 11.638 de 28 de Dezembro de 2007 alterou a legislação contábil brasileira para adaptar-se aos padrões internacionais de contabilidade já existentes em outros países. As profundas mudanças oriundas desta lei provocaram 
inúmeras Interpretações Técnicas a serem observadas, em especial ao Conselho Federal de Contabilidade através do Comitê de Pronunciamentos Contábeis que se encarregou de realizar tais interpretações, as quais permanecem em constante atualização, obrigando os profissionais da área contábil a estarem sempre atualizados no estudo da legislação societária.

Uma das mudanças estabelecidas foi a extinção do Ativo Permanente, subdividindo o mesmo em Imobilizado, Intangível, Investimento e Diferido, que será abordado a seguir.

\title{
3.1.1 Ativo Intangível e os contratos de concessão de serviços públicos
}

A Coordenadoria Técnica do Comitê de Pronunciamentos Contábeis, órgão disciplinador das Normas Internacionais de Contabilidade no Brasil aprovou em 05 de Dezembro de 2010 o Pronunciamento Técnico CPC 04 (R1) estabelecendo diretrizes para reconhecimento de um Ativo Intangível, definindo que um "Ativo intangível é um ativo não monetário identificável sem substância física, que proporciona direito de uso".

Conforme Gelbcke et al. (2018), ao abordar noções preliminares de reconhecimento de ativo intangível de concessões define que:

\begin{abstract}
A construção, a operação e a manutenção de alguns ativos públicos de infraestrutura, como por exemplo, rodovias, pontes, túneis, portos, aeroportos, redes de distribuição de energia, penitenciárias e hospitais são muitas vezes conduzidas por entidades particulares. Isso ocorre porque o Estado tem interesse em atrair a iniciativa privadas para o desenvolvimento dessas atividades. Em alguns casos, os ativos públicos de infraestrura já existem. Em outros, esses ativos são construídos pela iniciativa privada ou por empresas governamentais ou mesmo de economia mista. Esses tipos de contratados, onde o governo ou outro órgão do setor público (concedente) contrata uma entidade privada (a concessionário, também chamada de entidade operadora) para desenvolver, aperfeiçoar, operar ou manter seus ativos de infraestrutura, são denominados contratos de concessão de serviços, ou apenas concessões.
\end{abstract}

Já um Ativo Imobilizado é um bem tangível que possui substância física, ou seja, corpóreo, como descreve o Item 6 do CPC 27:

Correspondem aos direitos que tenham por objeto bens corpóreos destinados à manutenção das atividades da entidade ou exercidos com essa finalidade, inclusive os decorrentes de operações que transfiram a ela os benefícios, os riscos e o controle desses bens. (Item 6 - CPC 27)

Embora os bens pertencentes ao Porto estejam condicionados a manutenção de suas atividades, a SCPar Porto de Imbituba não possui o controle patrimonial desses bens, mas sim, quem detém o controle dos mesmos é o poder delegante, sendo que a utilização da infraestrutura portuária é por prazo determinado, sem que exista relação de propriedade desses bens.

A Resolução CFC 1.376/2011 do Conselho Federal de Contabilidade, a qual orienta sobre os direitos do concessionário sobre a infraestrutura, estabelece que:

A infraestrutura dentro do alcance desta Interpretação não será registrada como ativo imobilizado do concessionário porque o contrato de concessão não transfere ao concessionário $o$ direito de controlar $\circ$ uso da infraestrutura de serviços públicos. O concessionário tem acesso para 
VI CIDESPORT/2019

Congresso Internacional

de Desempenho Portuário

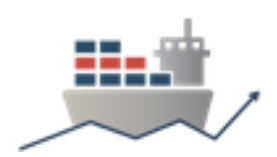

operar a infraestrutura para a prestação dos serviços públicos em nome do concedente, nas condições previstas no contrato. (Item 11 - ICPC 01 R1).

A orientação técnica contábil OCPC 05 - Contratos de Concessão aprovada pela Deliberação CVM n 654 de 28 de Dezembro de 2010, dispõe que:

Em geral, os contratos de concessão contém, além do componente de operação, também o componente de serviços de construção/melhorias, ou seja, o concessionário não somente opera a concessão como também tem obrigação de construir/melhorar antes e/ou durante o prazo da concessão. (Item 29 - OCPC 05).

Conforme Gelbcke et al. (2018), os ativos intangíveis decorrentes de concessão terão os principais aspectos:

a) a parte que concede o contrato de prestação de serviços (o concedente) é um órgão público ou uma entidade pública, ou uma entidade privada para a qual foi delegado o serviço;

b) a entidade operadora da concessão (o concessionário) é responsável ao menos por parte da gestão da infraestrutura e serviços relacionados, não atuando apenas como mero agente, em nome do concedente;

c) o contrato estabelece o preço inicial a ser cobrado pelo concessionário, regulamentando suas revisões durante a vigência do contrato de prestação de serviços;

d) o concessionário fica obrigado a entregar a infraestrutura ao concedente em determinadas condições especificadas no final do contrato, por um pequeno ou nenhum valor adicional, independentemente de quem tenha sido o seu financiador.

Desta forma, de acordo com os aspectos do convênio, deverá ser reconhecido um ativo intangível quando:

O concessionário deve reconhecer um ATIVO INTANGÍVEL à medida em que recebe o direito (autorização) de cobrar os usuários dos serviços públicos. Esse direito não constitui direito incondicional de receber caixa porque os valores são condicionados à utilização do serviço pelo público. (Item 17 - ICPC 01 R1)

Portanto, os investimentos efetuados pela SCPar Porto de Imbituba necessários para a exploração da atividade portuária deverão ser classificados como Ativo Intangível. Os investimentos que estão em construção poderão ser reconhecidos em uma conta contábil transitória (intangível em andamento) para posterior mensuração como Ativo Intangível.

Quanto ao reconhecimento e apropriação da despesa relativa à amortização dos ativos intangíveis da entidade, esta deverá observar que:

O ativo intangível deve ser amortizado dentro do prazo da concessão. $O$ cálculo deve ser efetuado de acordo com o padrão de consumo do benefício econômico por ele gerado, que normalmente se dá em função da curva de demanda. A estimativa da curva de amortização deve oferecer razoável confiabilidade, caso contrário, o método de linha reta (amortização linear) passa a ser o mais recomendado. (Item 42 - OCPC 05) 
VI CIDESPORT/2019

Congresso Internacional

de Desempenho Portuário

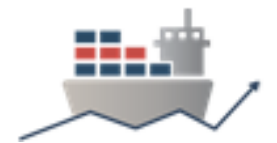

O Convênio de Delegação nº 01/2012, publicado no Diário Oficial da União em 30 de novembro de 2012, delegou pelo prazo de 25 (vinte e cinco anos) a exploração do Porto de Imbituba, que terá fim em 30 de novembro de 2037. Assim, nenhum ativo intangível poderá ser apropriado em prazo superior ao estabelecido, ou seja, todo cálculo de amortização deverá ser reconhecido com prazo máximo com base no término do Convênio supracitado.

\subsubsection{Exemplo de contabilização do Ativo Intangível}

Citamos o exemplo da construção de um edifício pela SCPar Porto de Imbituba, estimado em R \$ 10.000.000,00 (Dez Milhões de Reais):

Sobre os investimentos realizados durante a Construção da Obra, este poderá ser contabilizado da seguinte maneira:
Débito:
Ativo Intangível Construção
Ativo Não Circulante
Crédito:
Fornecedores a Pagar
Passivo Circulante

Após o bem estar disponível para uso e sua conclusão realizada, providenciara a contabilização pelo valor total do investimento na seguinte forma:
Débito:
Ativo Intangivel Construção
Ativo Não Circulante
Crédito:
Ativo Intangível
Ativo Não Circulante

O reconhecimento das despesas relativas ao investimento será apropriada no resultado, até o término do convênio de delegação, sendo contabilizada em conta redutora do ativo intangível, conforme se demonstra:
Débito:
Encargos de Amortização
Despesa/Resultado
Crédito:
(-) Amortização Acumulada
Ativo Não Circulante

O valor a ser reconhecido como despesa deverá ser proporcional a data de reconhecimento do bem até o término do convênio de delegação, considerando a hipótese de que o investimento acima citado seja finalizado em 01 de dezembro de 2015, o prazo para o término da concessão será de 22 (vinte e dois) anos ou 264 (duzentos e sessenta e quatro) meses. Aplicando o cálculo proporcional, o valor a ser considerado como despesa mensal será equivalente a $R \$ 37.878,79$, se utilizarmos o método de amortização linear.

\subsection{Aspectos Tributários}

Com as mudanças estabelecidas nos últimos anos na Legislação Societária no que tange a adoção contábil no Brasil as Normas Internacionais de Contabilidade (International Financial Reporting Standards - IFRS) e com o advento da Lei 11.638 de 28 de dezembro de 2007, a Receita Federal adaptou suas normas tributárias 
com o objetivo de neutralizar e disciplinar os aspectos tributários oriundos da convergência do Brasil às normas internacionais de contabilidade.

Com a publicação da Lei 12.973 de 13 de maio de 2014 houve o reconhecimento dos principais aspectos tributários em relação às novas normas contábeis, em especial a mensuração dos Ativos Intangíveis da empresa, sendo extinto o Regime Tributário de Transição - RTT.

\title{
3.2.1 Tributação do Imposto de Renda e da Contribuição Social
}

Atualmente, a empresa apura seus tributos pela sistemática de Apuração do Lucro Real, método pelo qual são definidos seus valores mediante apuração do seu lucro, de forma anual, com levantamento de balancetes mensais para recolhimento estimado de seus tributos.

A Lei 12.973 de 13 de maio de 2014 estabelece os valores mínimos que devem ser considerados para reconhecimento de um Ativo Intangível:

\begin{abstract}
Art. 15. O custo de aquisição de bens do ativo não circulante imobilizado e intangível não poderá ser deduzido como despesa operacional, salvo se o bem adquirido tiver valor unitário não superior a $R \$ 1.200,00$ (mil e duzentos reais) ou prazo de vida útil não superior a 1 (um) ano. (Lei 12.973 de 13 de Maio).
\end{abstract}

Quanto ao reconhecimento das despesas relativas aos investimentos em virtude do direito de exploração, este dispõe que:

\begin{abstract}
Art. 35. No caso de contrato de concessão de serviços públicos em que a concessionária reconhece como receita o direito de exploração recebido do poder concedente, o resultado decorrente desse reconhecimento deverá ser computado no lucro real à medida que ocorrer a realização do respectivo ativo intangível, inclusive mediante amortização, alienação ou baixa. (Vigência) (Lei 12.973 de 13 de Maio de 2014).
\end{abstract}

De acordo com a Legislação Tributária federal, nos aspectos de apuração do Imposto de Renda e Contribuição Social, é admissível como dedução da base de cálculo:

Art. 41. A amortização de direitos classificados no ativo não circulante
intangível é considerada dedutível na determinação do lucro real,
observado o disposto no inciso III do caput do art. 13 da Lei no 9.249 , de
26 de dezembro de 1995. (Vigência). (Lei 12.973 de 13 de Maio de 2014).

No tocante a mensuração tributária dos gastos relativos à recuperação da infraestrutura não operável e aquisição de novos bens, deverá ser reconhecida de acordo com o Decreto 9.580 de 26 de novembro de 2018 (Regulamento do Imposto de Renda), sendo que em seu Art. 331 estabelece o que deverá ser amortizado:

Art. 331. Poderão ser amortizados os capitais aplicados na aquisição de direitos cuja existência ou exercício tenha duração limitada ou de bens cuja utilização pelo contribuinte tenha o prazo legal ou contratualmente limitado, tais como ( Lei $^{\circ} 4.506$, de 1964, art. 58 ; e Decreto-Lei n 1.483, de 1976, art. $\left.\underline{5^{\circ}}\right)$ :

I - patentes de invenção, fórmulas e processos de fabricação, direitos autorais, licenças, autorizações ou concessões; 
VI CIDESPORT/2019

Congresso Internacional

de Desempenho Portuário

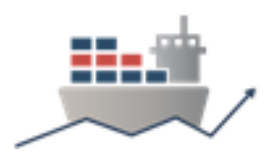

II - custo de aquisição, prorrogação ou modificação de contratos e direitos de qualquer natureza, inclusive de exploração de fundos de comércio;

III - custos de construções ou benfeitorias em bens locados ou arrendados, ou em bens de terceiros, quando não houver direito ao recebimento de seu valor; IV - o valor de direitos contratuais de exploração de florestas de que trata o art. 334 ; e

$\mathrm{V}$ - os demais direitos classificados no ativo não circulante intangível.

O valor a ser considerado como despesa deverá ser reconhecida de forma proporcional, conforme estabelecido no Regulamento de Imposto de Renda, nas seguintes condições:

\begin{abstract}
Art. 332. A quota de amortização dedutível em cada período de apuração será determinada pela aplicação da taxa anual de amortização sobre o valor original do capital aplicado. (Lei $n^{\circ} 4.506$, de 1964, art. 58, § $1^{\circ}$ );

$\S 1^{\circ}$ Se a amortização tiver inicio ou terminar no curso do período de apuração, ou se este tiver duração inferior a doze meses, a taxa anual será ajustada proporcionalmente ao período de amortização.

$\S 2^{\circ} \mathrm{A}$ amortização poderá ser apropriada em quotas mensais, dispensado o ajuste da taxa para o capital aplicado ou baixado no curso do mês.

Art. 333. A taxa anual de amortização será estabelecida tendo em vista o número de anos de existência do direito. (Lei n 4.506, de 1964, art. 58, $\S 1^{\circ}$ ).
\end{abstract}

De acordo com o convênio de delegação, os investimentos realizados pela SCPar Porto de Imbituba S.A. estão condicionados a manutenção do contrato, portanto, o prazo da existência do direito será compreendido entre a data de conclusão do investimento e o término do convênio de delegação.

Em caso de extinção do contrato sem que os saldos estejam reconhecidos em sua integridade como despesa, ou seja, apropriados, o saldo a ser amortizado deverá ser reconhecido em sua integridade em um único exercício:

$\S 3^{\circ}$ Se a existência ou o exercício do direito, ou a utilização do bem, terminar antes da amortização integral de seu custo, o saldo não amortizado constituirá encargo no período de apuração em que se extinguir o direito ou terminar a utilização do bem . (Art. 330, § $3^{\circ}$, Decreto 9.580/2018)

Assim, o prazo de utilização da despesa deverá ser fracionado de acordo com o prazo do convênio de delegação, sendo que sua antecipação em períodos menores acarretará em evasão fiscal pelo contribuinte, visto que os critérios utilizados estão em desacordo com a Legislação Tributária.

\title{
3.2.2 Tributação da contribuição para o PIS/PASEP e COFINS
}

A companhia apura seus tributos de Pis/Pasep e Cofins através do regime de incidência não cumulativa, instituídos pela Lei 10.637 de 30 de novembro 2002 e 10.833 de 29 de dezembro de 2003, respectivamente, atualizada pela Lei 12.973 de 13 de maio de 2014, regime pelo qual é permitido a dedução de créditos com base em custos, despesas e encargos da pessoa jurídica.

Devido a semelhança da Legislação tributária para ambos os tributos, será abordado apenas a Legislação correspondente a Contribuição para o Financiamento da Seguridade Social (COFINS).

Na execução de contratos de concessão de serviços públicos, a Lei 12.973 de 13 de maio de 2014 estabelece que: 


\section{CIDESPORT/2019 \\ Congresso Internacional \\ de Desempenho Portuário}

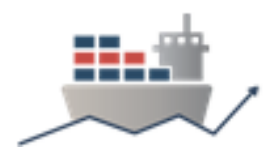

$\S 29$. Na execução de contratos de concessão de serviços públicos, os créditos gerados pelos serviços de construção, recuperação, reforma, ampliação ou melhoramento de infraestrutura, quando a receita correspondente tiver contrapartida em ativo intangível, representativo de direito de exploração, ou em ativo financeiro, somente poderão ser aproveitados, no caso do ativo intangível, à medida que este for amortizado e, no caso do ativo financeiro, na proporção de seu recebimento, excetuado, para ambos os casos, o crédito previsto no inciso VI do caput. (Incluído pela Lei no 12.973 de 13 de Maio 2014).

Sobre a utilização de créditos relativos à aquisição de bens no ativo intangível, o Art. $3^{\circ}$ da Lei 10.833 de 2003, dispõe que:

Art. 3o Do valor apurado na forma do art. 2ำ a pessoa jurídica poderá descontar créditos calculados em relação a:

$\mathrm{XI}$ - bens incorporados ao ativo intangível, adquiridos para utilização na produção de bens destinados a venda ou na prestação de serviços. (Incluído pela Lei n 12.973 de 13 de Maio 2014).

Para que obtenhamos o valor a ser considerado para determinação do crédito, sua base de cálculo tributária será:

III - dos encargos de depreciação e amortização dos bens mencionados nos incisos VI, VII e XI do caput, incorridos no mês (Lei n ${ }^{\circ} 12.973$ de 13 de Maio 2014).

Para obtenção da determinação da alíquota do crédito a ser utilizado conforme disposto anteriormente aplicar-se-á:

$\S 1$ o Observado o disposto no $\S 15$ deste artigo, o crédito será determinado mediante a aplicação da alíquota prevista no caput do art. 20 desta Lei sobre o valor: (Redação dada pela Lei $n^{\circ} 11.727$, de 2008) (Produção de efeitos) (Art. 3o, XI, § 1ㅇ , Lei 10.833 de 2003).

Art. 2o Para determinação do valor da COFINS aplicar-se-á, sobre a base de cálculo apurada conforme o disposto no art. 10, a alíquota de 7,6\% (sete inteiros e seis décimos por cento). (Lei 10.833 de 29 de Dezembro de 2003).

As hipóteses de vedação da utilização do crédito acontecerão nas seguintes situações:

§ 2o Não dará direito a crédito o valor: (Redação dada pela Lei n 10.865 , de 2004)

I - de mão-de-obra paga a pessoa física; e (Incluído pela Lei no 10.865 , de 2004)

II - da aquisição de bens ou serviços não sujeitos ao pagamento da contribuição, inclusive no caso de isenção, esse último quando revendidos ou utilizados como insumo em produtos ou serviços sujeitos à alíquota 0 (zero), isentos ou não alcançados pela contribuição. (Incluído pela Lei n ${ }^{\circ}$ 10.865, de 2004)

§ 3o O direito ao crédito aplica-se, exclusivamente, em relação:

I - aos bens e serviços adquiridos de pessoa jurídica domiciliada no País;

II - aos custos e despesas incorridos, pagos ou creditados a pessoa jurídica. (Art. $3^{\circ} \S 2$ o da Lei 10.833 de 29 de Dezembro de 2003). 
VI CIDESPORT/2019

Congresso Internacional

de Desempenho Portuário

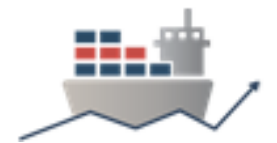

Desta forma, poderá ser utilizado como crédito de Pis e Cofins o valor correspondente a alíquota de $1,65 \%$ e $7,60 \%$, respectivamente, atribuída a quantia da amortização realizada naquele mês, deste que respeite todas as condições de utilização do crédito.

\section{RESULTADOS OBTIDOS}

Considerando que uma das principais missões da SCPar Porto de Imbituba S.A. é o desenvolvimento e modernização das instalações portuárias, os valores decorrentes de investimentos em infraestrutura e modernização tem se tornado cada vez mais significativo em suas finanças, refletindo diretamente na apresentação de seus demonstrativos contábeis e apuração dos tributos na qual esta submetida.

Desta forma, os resultados alcançados com o presente relato técnico, buscam trazer subsídios para a adequada contabilização destes valores a luz das Normas Internacionais de Contabilidade, proporcionando maior segurança e confiabilidade nos números apresentados pela companhia, com maior preparo das informações contábeis da instituição.

Somada a isto, têm-se os ganhos pela adequada tributação destes investimentos, prevenindo ações fiscais e tributárias ao considerar a segurança e correta apuração dos encargos tributários envolvidos nestas transações.

\section{CONCLUSÕES}

É de fundamental importância que a SCPar Porto de Imbituba S.A., assim como os demais portos do país mensurem de forma adequada os investimentos realizados em seus complexos portuários.

A companhia identificou a necessidade de analisar o contexto no qual foi inserida e suas principais particularidades no que tange os aspectos de registro contábil e aproveitamento de créditos tributários decorrentes dos investimentos em sua infraestrutura.

Neste contexto, o presente estudo identificou como solução mais adequada o registro dos investimentos em modernização da infraestrutura e aquisição de bens aqueles previstos nas Normas Internacionais de Contabilidade para contabilização como Ativo Intangível, tendo em vista não ser de sua propriedade as instalações, tendo somente um contrato para exploração a titulo de delegação entre a União e o Estado de Santa Catarina.

Da mesma forma, os aspectos tributários devem estar em sinergia com a condição de ativo intangível do delegatário dos serviços públicos portuários, registrando os respectivos débitos e créditos fiscais de maneira prudente e em consonância com a legislação tributária vigente.

Como recomendação, as pesquisas futuras podem abordar os aspectos de mensuração das demais tipologias de administração portuária, tais quais: terminais privados, companhias docas, entre outros, assim como a análise da adequada mensuração contábil pelas demais autoridades portuárias brasileiras.

\section{REFERÊNCIAS}


VI CIDESPORT/2019

Congresso Internacional

de Desempenho Portuário

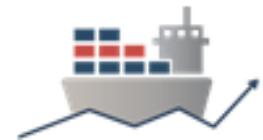

AGÊNCIA NACIONAL DE TRANSPORTES AQUAVIARIOS. Resolução Normativa $n^{\circ} 29 n^{\circ} 28$ de março de 2019. Disponível em: <http://www.portal.antaq.gov.br>.

Acesso em: 31 jul. 2019.

BRASIL: Lei No 11.638, de 28 de Dezembro de 2007. Disponível em

$<$ http://www.planalto.gov.br/ccivil 03/ ato2007-2010/2007/lei//11638.htm>. Acesso em 31 jul. 2019.

BRASIL: Lei № 12.973, de 13 de Maio de 2014. Disponível em <http://www.planalto.gov.br/ccivil 03/ Ato2011-2014/2014/Lei/L12973.htm>.

Acesso em 31 jul. 2019.

BRASIL: Lei No 10.637, de 30 de Dezembro de 2002. Disponível em <http://www.planalto.gov.br/ccivil 03/LEIS/2002/L10637.htm>. Acesso em 31 jul. 2019.

BRASIL: Lei No 10.833, de 29 de Dezembro de 2003. Disponível em $<$ http://www.planalto.gov.br/ccivil 03/LEIS/2003/L10.833.htm>. Acesso em 31 jul. 2019.

BRASIL: Decreto $n^{\circ} 9.580$, de 22 de Novembro de 2018. Disponível em <http://www.planalto.gov.br/ccivil 03/ ato2015-2018/2018/decreto/D9580.htm>. Acesso em 31 jul. 2019.

COMITÊ DE PRONUNCIAMENTOS CONTÁBEIS (CPC). Pronunciamento Técnico Contábil no 004 (R1), de 02 de dezembro de 2010. Disponível em: $<$ http://www.cpc.org.br> . Acesso em 31 jul. 2019.

COMITÉ DE PRONUNCIAMENTOS CONTÁBEIS (CPC). Pronunciamento Técnico Contábil no 004 (R1), de 02 de dezembro de 2010. Disponível em: <http://www.cpc.org.br> . Acesso em 31 jul. 2019.

COMITÉ DE PRONUNCIAMENTOS CONTÁBEIS (CPC). Pronunciamento Técnico Contábil ${ }^{\circ}$ 027, de 31 de julho de 2009. Disponível em:

<http://www.cpc.org.br> . Acesso em 31 jul. 2019.

COMITÉ DE PRONUNCIAMENTOS CONTÁBEIS (CPC). Orientação $n^{\circ} 005$, de 29 de dezembro de 2010. Disponível em: <http://www.cpc.org.br> . Acesso em 31 jul. 2019.

COMITÊ DE PRONUNCIAMENTOS CONTÁBEIS (CPC). Orientação $n^{\circ} 005$, de 29 de dezembro de 2010. Disponível em: <http://www.cpc.org.br> . Acesso em 31 jul. 2019.

COMITEE DE PRONUNCIAMENTOS CONTÁBEIS (CPC). Interpretação $n^{\circ} 001$, de 15 de dezembro de 2011. Disponível em: <http://www.cpc.org.br> . Acesso em 31 jul. 2019.

COMISSÃO DE VALORES MOBILIARIOS. Deliberação CVM n 654, de 28 de dezembro de 2010. Disponível em: 
VI CIDESPORT/2019

Congresso Internacional

de Desempenho Portuário

<http://www.cvm.gov.br/legislacao/deliberacoes/deli0600/deli654.html>. Acesso em: 31 jul. 2019.

CONSELHO FEDERAL DE CONTABILIDADE. Resolução $1.376 \mathrm{n}^{\circ} 08$ de dezembro de 2011. Disponível em: <http://www.cfc.org.br>. Acesso em: 31 jul. 2019.

GELBCKE, E.R.; MARTINS, E.; IUDICÍBUS, S.; SANTOS, A.D. Manual de Contabilidade Societária: aplicável a todas as sociedades de acordo com as normas internacionais e do CPC. São Paulo: Atlas, 2018.

SCPAR PORTO DE IMBITUBA S.A. Convênio de Delegação nº 01/2012 de 26 de novembro de 2012. Brasília, 2012. 